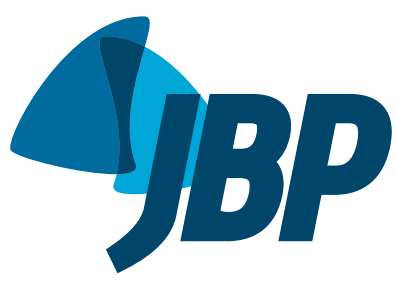

1. Divisão de Pneumologia, Instituto do Coração, Hospital das Clínicas, Faculdade de Medicina, Universidade de São Paulo, São Paulo (SP) Brasil.

2. Fundação Jorge Duprat Figueiredo de Segurança e Medicina do Trabalho - FUNDACENTRO - São Paulo (SP) Brasil.

Submitted: 24 November 2015 Accepted: 17 March 2017

Study carried out at the Faculdade de Medicina, Universidade de São Paulo, São Paulo (SP) Brasil.

\section{Effective tobacco control measures: agreement among medical students}

\author{
Stella Regina Martins ${ }^{1}$, Renato Batista Paceli ${ }^{1}$, Marco Antônio Bussacos², \\ Frederico Leon Arrabal Fernandes' ${ }^{1}$, Gustavo Faibischew Prado', \\ Elisa Maria Siqueira Lombardi1', Mário Terra-Filho', Ubiratan Paula Santos ${ }^{1}$
}

\begin{abstract}
Objective: To determine the level of agreement with effective tobacco control measures recommended by the World Health Organization and to assess the attitudes toward, knowledge of, and beliefs regarding smoking among third-year medical students at University of São Paulo School of Medicine, located in the city of São Paulo, Brazil. Methods: Between 2008 and 2012, all third-year medical students were invited to complete a self-administered questionnaire based on the Global Health Professionals Student Survey and its additional modules. Results: The study sample comprised 556 students. The level of agreement with the World Health Organization recommendations was high, except for the components "received smoking cessation training" and "raising taxes is effective to reduce the prevalence of smoking". Most of the students reported that they agree with banning tobacco product sales to minors (95\%), believe that physicians are role models to their patients (84\%), and believe that they should advise their patients to quit cigarette smoking (96\%) and using other tobacco products (94\%). Regarding smoking cessation methods, most of the students were found to know more about nicotine replacement therapy than about non-nicotine therapies $193 \%$ vs. $53 \%)$. Only $37 \%$ of the respondents were aware of the importance of educational antismoking materials, and only $31 \%$ reported that they believe in the effectiveness of encouraging their patients, during medical visits. In our sample, the prevalence of current cigarette smoking was 5.23\%; however, $43.82 \%$ of the respondents reported having experimented with water-pipe tobacco smoking. Conclusions: Our results revealed the need to emphasize to third-year medical students the importance of raising the prices of and taxes on tobacco products. We also need to make students aware of the dangers of experimenting with tobacco products other than cigarettes, particularly water-pipe tobacco smoking.
\end{abstract}

Keywords: Tobacco products; Health policy; Education, medical, undergraduate; Health knowledge, attitudes, practice.

\section{INTRODUCTION}

A decade ago, the World Health Organization created the Framework Convention on Tobacco Control, the first international public health convention aimed at decreasing tobacco-related morbidity and mortality. ${ }^{(1)}$ Smoking remains an important public health problem, because it is the major preventable cause of premature morbidity and mortality. In the last century, tobacco use killed 100 million people, and, if current smoking patterns continue, it will kill around 1 billion people in the 21st century. ${ }^{(1)}$ Tobacco use has also been recognized as one of the leading risk factors for noncommunicable diseases. ${ }^{(1)}$ To achieve abstinence, smokers need repeated attempts to quit smoking, because lapses and relapses are frequent during treatment. For this reason, nicotine dependence is being regarded as a chronic disease. ${ }^{(2)}$

Based on evidence and best practices, the World Health Organization also developed guidelines that provide some measures to help countries to implement and manage tobacco control policies. These measures are known as MPOWER, an acronym for Monitoring tobacco use; Protecting people from tobacco smoke; Offering help to quit tobacco use; Warning about the dangers of tobacco; Enforcing bans on tobacco advertising; and Raising taxes on tobacco products. ${ }^{(3)}$

Medical schools need to train their future doctors in public health policies on tobacco control in order to reduce smoking initiation and smoking-related morbidity and mortality. In the future, we expect aspiring physicians to be able to play an important and unique role in preventing smoking initiation and decreasing the prevalence of smoking by advising, encouraging, and assisting helping their patients to quit smoking.

For these reasons, article 12 of the Framework Convention on Tobacco Control guidelines ${ }^{(4)}$ states that the curricula of medical schools must include tobacco control, providing students with effective and appropriate training.

The aims of the present study were to determine the level of agreement with the World Health Organization 
MPOWER components among third-year medical students at the University of São Paulo School of Medicine, located in the city of São Paulo, Brazil, and to assess their attitudes, knowledge, and beliefs about smoking.

\section{METHODS}

Between 2008 and 2012, third-year medical students at the University of São Paulo School of Medicine were invited to complete a self-administered questionnaire based on a standardized school-based survey for third-year medical - the Global Health Professionals Student Survey-and its additional modules. ${ }^{(5)}$ The participation was voluntary, and the completion of the questionnaire occurred during regular classes. During the study period, the medical curriculum remained the same. All students who agreed to participate gave written informed consent. The local research ethics committee of the institution approved the study. (Process no. 0277/08).

Students who reported having smoked 100 or more cigarettes in their lifetime and, at the time of the survey, were still smoking were classified as current cigarette smokers. We classified as experimentation with water pipe and other forms of tobacco use those students who reported having ever experimented with those products (e.g., having taken at least a few puffs).

Descriptive analyses and comparisons of the proportions of positive responses between smokers and nonsmokers were carried out. We used the chi-square test or Fisher's exact test, when appropriate, to verify associations between variables. Values of $p<0.05$ were considered statistically significant. The data were analyzed with the Statistical Analysis System, version 9.0 (SAS Institute Inc., Cary, NY, USA).

\section{RESULTS}

Of a total sample of 900 students, 556 (62\%) completed the questionnaire. The number of answers often varied because not all respondents answered all of the questions in each MPOWER component. The mean age of male and female respondents ( $n$
$=548)$ was $22.24 \pm 2.85$ years and $21.90 \pm 2.17$ years, respectively.

All of the smokers in the sample agreed about the importance of monitoring and registering the smoke status of their patients in medical charts (Table 1). Over $90 \%$ of the aspiring physicians agreed with protecting the population against environmental tobacco smoke exposure. However, few students reported having received smoking cessation training to help them with their future patients who smoke. Almost the majority of the students had been warned about the harmful health effects of tobacco smoking. More than $80 \%$ of all the respondents supported the total ban of sponsorships, promotions, and advertising of tobacco products. Nevertheless, only a few students agreed on the importance of increasing taxes as an effective measure to reduce the prevalence of smoking. There were no statistically significant differences between males and females regarding any of the six MPOWER components.

The majority of the responding students agreed with the measure that protects minors from buying tobacco products (Table 2 ). Almost all smokers and nonsmokers agreed that they should receive specific training on smoking cessation and that it is important to advise their patients to quit smoking. Although the proportion of nonsmokers who believed that health professionals are role models for their patients and the public was greater than was that of smokers who had the same belief ( $84.60 \%$ vs. $78.57 \%$ ), the difference was not significant. More than $90 \%$ of the respondents agreed that physicians should routinely advise their patients to quit smoking and using other tobacco products, and they believed that the attitude of giving this sort of advice increases the chances of smoking cessation. Nonsmoking students believed that health professionals who smoke are less likely to advise their patients to quit smoking $(p<0.05)$. Half of the smokers and less than half of the nonsmokers reported having discussed the reasons that lead someone to start smoking. Less than $40 \%$ of the respondents reported having been taught about the importance to offer their patients educational materials about smoking cessation.

Regarding the issues related to treatment, both smoking and nonsmoking students showed a greater

Table 1. Agreement with the MPOWER measures among undergraduate medical students, by smoking status. ${ }^{b}$

\begin{tabular}{|c|c|c|c|c|}
\hline \multirow[t]{2}{*}{ Measure } & \multicolumn{2}{|c|}{ Group ${ }^{c}$} & \multirow[t]{2}{*}{ p* } & \multirow{2}{*}{$\begin{array}{c}\text { Total } \\
\text { n/N (\%) }\end{array}$} \\
\hline & $\begin{array}{l}\text { Smoker } \\
\text { n/N (\%) }\end{array}$ & $\begin{array}{c}\text { Nonsmoker } \\
\text { n/N (\%) }\end{array}$ & & \\
\hline Monitoring: registry in medical charts & $28 / 28(100.00)$ & $499 / 507(98.42)$ & NS & $527 / 535(98.50)$ \\
\hline Protecting: smoking ban in all public enclosed places & $27 / 27(100.00)$ & $477 / 502(95.02)$ & NS & $504 / 529(95.27)$ \\
\hline Offering: received smoking cessation training & $9 / 28(32.14)$ & $111 / 505(21.98)$ & NS & $120 / 533(22.51)$ \\
\hline Warning: taught about health risks of smoking & $27 / 28(96.43)$ & $493 / 507(97.24)$ & NS & $520 / 535(97.20)$ \\
\hline $\begin{array}{l}\text { Enforcing: total ban of advertising, promotion, and } \\
\text { sponsorship }\end{array}$ & $22 / 28(78.57)$ & $411 / 500(82.20)$ & NS & $433 / 528(82.01)$ \\
\hline $\begin{array}{l}\text { Raising: raising taxes is effective to reduce the } \\
\text { prevalence of smoking }\end{array}$ & $11 / 28(39.29)$ & $169 / 506(33.40)$ & NS & $180 / 534(33.71)$ \\
\hline
\end{tabular}

NS: not significant. aWorld Health Organization. (3) bSome denominators vary because of missing data. ${ }^{c}$ Cigarette smokers/nonsmokers. ${ }^{*}$ Chi-square test. 
knowledge about nicotine replacement therapies than about other types of smoking cessation therapies. Only one-third of the respondents believed in the importance of encouraging smokers, during medical visits, to try to quit smoking. There were no statistically significant differences between males and females regarding the attitudes toward and knowledge about smoking.

The prevalence of current cigarette smoking was low $(5.23 \%)$; however, the prevalences of experimenting with cigars, pipes, cheroots, and other tobacco products $(21.23 \%)$ and experimenting with water-pipe tobacco smoking (43.82\%) were higher (Table 3). These prevalences were significantly higher among males.

Table 4 shows that less than $20 \%$ of the respondents were exposed to secondhand tobacco smoke in their households. Although the difference was not significant, the analysis revealed that males were less exposed to passive smoking than females: zero days of secondhand tobacco smoke exposure (79.83\% vs. $82.97 \%$ ) and five or more days of secondhand exposure (9.44\% vs. 7.57\%).

\section{DISCUSSION}

Future physicians should be empowered to assume their role in tobacco control. To make this happen, they must learn about the six most effective public policy measures for controlling the tobacco epidemic and be trained in smoking cessation over the medical course.

The present study revealed a high level of agreement with the majority of the MPOWER components. In the third year of the medical school, we found that students had already been properly informed about the importance of monitoring and registering the smoking status of the patients in medical charts as a means to track down and measure the prevalence of smoking among the population; a similar outcome was found in a study carried out at the University of Malta. ${ }^{(6)}$

The students in our sample were more aware of the importance of protecting people from secondhand tobacco smoke $(95,2 \%)$ than were medical students in Germany (80\%), Poland (74,5\%), and Spain (73,9\%). (7) In addition, they showed having sufficient knowledge about the damages caused by smoking, reporting that they had been taught and warned about the health risks of smoking at their medical school. This knowledge could have also come from public health policies; since 1988, Brazil has adopted health warnings on all packages of tobacco products. In 2001, the first round of pictorial warnings covering $100 \%$ of one side of cigarette packs and at points of

Table 2. Attitudes toward, knowledge of, and beliefs regarding smoking among medical undergraduate students, by smoking status. ${ }^{a}$

\begin{tabular}{|c|c|c|c|c|}
\hline \multirow{2}{*}{$\begin{array}{l}\text { Issues related to smoking education } \\
\text { in the medical curriculum }\end{array}$} & \multicolumn{2}{|c|}{ Group $^{b}$} & \multirow[t]{2}{*}{ p* } & \multirow{2}{*}{$\begin{array}{l}\text { Total } \\
\text { n/N (\%) }\end{array}$} \\
\hline & $\begin{array}{l}\text { Smoker } \\
\mathrm{n} / \mathrm{N}(\%)\end{array}$ & $\begin{array}{l}\text { Nonsmoker } \\
\mathrm{n} / \mathrm{N}(\%)\end{array}$ & & \\
\hline 1. Should sales to minors be banned? & $26 / 28(92.86)$ & $479 / 502(95.42)$ & NS & $505 / 530(95.28)$ \\
\hline $\begin{array}{l}\text { 2. Should health professionals receive specific training in } \\
\text { smoking cessation techniques? }\end{array}$ & $26 / 28(92.86)$ & $482 / 503(95.83)$ & NS & $508 / 531(95.67)$ \\
\hline $\begin{array}{l}\text { 3. Do health professionals serve as role models for their } \\
\text { patients and the public? }\end{array}$ & $22 / 28(78.57)$ & $423 / 500(84.60)$ & NS & $445 / 528(84.28)$ \\
\hline $\begin{array}{l}\text { 4. Should health professionals routinely advise their } \\
\text { smoking patients to quit? }\end{array}$ & $28 / 28(100.00)$ & $481 / 503(95.63)$ & NS & $509 / 531(95.86)$ \\
\hline $\begin{array}{l}\text { 5. Should health professionals routinely advise their } \\
\text { patients who use tobacco products other than cigarettes } \\
\text { to stop using those products? }\end{array}$ & $28 / 28(100.00)$ & $471 / 503(93.64)$ & NS & $499 / 531(93.97)$ \\
\hline $\begin{array}{l}\text { 6. Should health professionals provide information about } \\
\text { smoking cessation to patients? }\end{array}$ & $28 / 28(100.00)$ & $501 / 503(99.60)$ & NS & $529 / 531(99.62)$ \\
\hline $\begin{array}{l}\text { 7. Do the possibilities to quit smoking increase if a health } \\
\text { professional provide advice? }\end{array}$ & $26 / 28(92.86)$ & $454 / 495(91.72)$ & NS & $480 / 523(91.78)$ \\
\hline $\begin{array}{l}\text { 8. Are smoking health professionals less likely to advise } \\
\text { smoking patients to quit smoking? }\end{array}$ & $12 / 27(44.44)$ & $321 / 502(63.94)$ & $\hat{0.05}$ & $333 / 529(62.95)$ \\
\hline $\begin{array}{l}\text { 9. Have you discussed the reasons why people smoke } \\
\text { during your medical school classes? }\end{array}$ & $14 / 28(50)$ & $248 / 507(48.92)$ & NS & $262 / 535(48.97)$ \\
\hline $\begin{array}{l}\text { 10. Have you been taught about the importance of } \\
\text { providing educational materials to support smoking } \\
\text { cessation during your medical school classes? }\end{array}$ & $9 / 28(32.14)$ & $190 / 505(37.62)$ & NS & $199 / 533(37.34)$ \\
\hline $\begin{array}{l}\text { 11. Have you heard about smoking cessation treatment } \\
\text { with nicotine replacement therapy (patch and gum)? }\end{array}$ & $26 / 28(92.86)$ & 473/507 (93.29) & NS & $499 / 535(93.27)$ \\
\hline $\begin{array}{l}\text { 12. Have you heard about smoking cessation treatment } \\
\text { with bupropion or nortriptyline? }\end{array}$ & $17 / 28(60.71)$ & $266 / 505(52.67)$ & NS & $283 / 533(53.10)$ \\
\hline $\begin{array}{l}\text { 13. Do you believe that encouraging smokers to think } \\
\text { about quitting and trying to stop smoking, during medical } \\
\text { visits, is an effective method for smoking cessation? }\end{array}$ & $9 / 28(32.14)$ & $159 / 507(31.36)$ & NS & $168 / 535(31.40)$ \\
\hline
\end{tabular}

NS: not significant. aSome denominators vary because of missing data. ${ }^{\mathrm{b}}$ Cigarette smokers/nonsmokers. ${ }^{*} \mathrm{Chi}-$ square test. 
Table 3. Prevalence of smoking and tobacco experimentation among medical undergraduate students, by gender. ${ }^{\text {a }}$

\begin{tabular}{lcccc}
\multicolumn{1}{c}{ Tobacco use } & Female & Male & p* & $\begin{array}{c}\text { Total } \\
\text { n/N (\%) }\end{array}$ \\
& $\mathbf{n} / \mathbf{N}(\%)$ & $\mathbf{n} / \mathbf{N}(\%)$ & & $28 / 535(5.23)$ \\
Current cigarette smokers ${ }^{b}$ & $5 / 227(2.20)$ & $23 / 308(7.47)$ & $<0.01$ & $28 / 551(21.23)$ \\
$\begin{array}{l}\text { Other forms of experimentation (cigars, pipes, } \\
\text { cheroots, chewed, and sniffed) }\end{array}$ & $23 / 235(9.79)$ & $94 / 316(29.75)$ & $<0.0001$ & $117 / 5516$ \\
Water-pipe tobacco smoking experimentation $^{c}$ & $86 / 235(36.60)$ & $155 / 315(49.21)$ & $<0.005$ & $241 / 550(43.82)$ \\
\hline
\end{tabular}

NS: not significant. a Some denominators vary because of missing data. befined as lifetime smoking $\geq 100$ cigarettes and currently reporting to be a cigarette smoker. 'Defined as having ever used the product once. ${ }^{*}$ Chi-square test.

Table 4. Prevalence of secondhand smoke exposure at home in the last seven days among medical undergraduate students, by smoking status. ${ }^{a}$

\begin{tabular}{|c|c|c|c|c|}
\hline \multirow[t]{2}{*}{ Secondhand smoke exposure, days } & \multicolumn{2}{|c|}{ Group $^{b}$} & \multirow[t]{2}{*}{ p* } & \multirow{2}{*}{$\begin{array}{c}\text { Total } \\
\text { n/N (\%) }\end{array}$} \\
\hline & $\begin{array}{l}\text { Smoker } \\
\text { n/N (\%) }\end{array}$ & $\begin{array}{c}\text { Nonsmoker } \\
\text { n/N (\%) }\end{array}$ & & \\
\hline 0 & $20 / 28(71.43)$ & $413 / 502(82.27)$ & NS & $433 / 530(81.70)$ \\
\hline $1-2$ & $1 / 28(3.57)$ & $11 / 502(2.19)$ & NS & $12 / 530(2.26)$ \\
\hline $3-4$ & $2 / 28(7.14)$ & $39 / 502(7.77)$ & NS & $41 / 530(7.74)$ \\
\hline$\geq 5$ & $5 / 28(17.86)$ & $39 / 502(7.77)$ & NS & $44 / 530(8.30)$ \\
\hline
\end{tabular}

NS: not significant. aSome denominators vary because of missing data. ${ }^{b}$ Cigarette smokers/nonsmokers. ${ }^{*}$ Chisquare test.

sale began to appear. We are currently in the third round of the warning images. ${ }^{(8-10)}$

The enforcement of the total ban of promotion and sponsorship of tobacco products was a consensus among the students. This generation has been protected against the tobacco industry advertising, because Brazil has banned sponsorship of all tobacco advertising, except at the points of sale, since $2000 .{ }^{(8-10)}$ In contrast, our sample of students showed little knowledge about some of the topics related to smoking cessation training. Our poor result was similar to that in a study carried out in Italy. ${ }^{(11)}$ Perhaps these findings can be explained by the fact that the respondents were still at the beginning of their medical course, and the treatment approach to smoking cessation has yet to be taught.

On the subject related to the importance of raising tobacco taxes, the results showed that few medical students agreed with this important recommendation, showing their little knowledge on the topic. Increasing taxes on and prices of tobacco products is one of the most effective measures for reducing smoking initiation among the youth, and it is also significantly effective in reducing consumption. ${ }^{(4)}$ The Brazilian Telephone-based System for the Surveillance of Risk and Protective Factors for Chronic Diseases carried out two surveys (in 2006 and 2013) among smokers aged 18 years or older that showed that the prevalence of smoking decreased from $15.72 \%$ to $11.30 \%$. ${ }^{(12)}$ According to the International Tobacco Control Policy Evaluation Project/Brazil, taxes increased the prices of tobacco products by $30 \%$ in 2007 , and taxes on retail pricing increased to $65 \%$ in 2009 . This might have had an impact on the decrease in the prevalence of smoking. ${ }^{(8)}$ Young people are two or three times more affected by tax and price rises than older smokers. ${ }^{(13)}$ These measures reduce their chances of moving from tobacco experimentation to addiction. Medical students are the health practitioners of the future, and they need to know that this is the most important public health measure for tobacco control. ${ }^{(4,10)}$ This subject must be taught in medical schools, and more discussions on this topic should be encouraged in order to strengthen the understanding of the positive impact of these measures by future doctors. We can observe in the present study and in another one carried out in four European countries $^{(7)}$ that there is a trend toward awareness of and agreement on an underage tobacco sales ban. Our research raised another interesting point because almost all of the respondents recognized that specific training in smoking cessation techniques is relevant to their education. The same result was found in a study carried out in India. (14)

The results showed a trend when the medical students recognized that they serve as role models for the general population. The respondents thought they should routinely offer advice or information to their patients who smoke cigarettes and use other tobacco products about quitting smoking and that the possibilities of smoking cessation increase with motivational intervention. Therefore, to improve the effectiveness of medical students as role models, medical schools need to have a comprehensive undergraduate curriculum that teaches issues related to tobacco smoking prevention and cessation. These results were also found in other studies. ${ }^{(7,14,15)}$

Physicians dedicate their lives to taking care of the greatest human patrimony; because of that, unfortunately, they have little time to take care of their own health. The findings showed a statistical significance on the issue related to their beliefs regarding the importance of the smoking status of health care professionals. Nonsmoking students more often believed, when compared with their smoking colleagues, that health professionals who smoke have 
fewer chances to counsel their smoking patients to stop smoking. Because nicotine is an addictive substance, it is important to highlight the ethical role played by medical schools in offering smoking cessation treatment to their motivated students. ${ }^{(12,16,17)}$

Less than half of respondents said that, during their classes, they had discussed the reasons why people smoke; this corroborates the findings of another study, which showed slightly higher results than ours. ${ }^{(6)}$ We emphasize that teaching about tobacco use triggers is essential for a comprehensive and correct approach to smoking.

Only a little over a third of the respondents reported having been taught that educational materials are an effective support for smoking cessation. This fact shows that this issue had not been addressed as effectively as it was in the University of Malta. ${ }^{(6)}$

The questions related to the pharmacological treatment for supporting smoking cessation revealed that the majority of the respondents had good knowledge of nicotine replacement therapies, and this result is similar to those seen in Germany and lower than those found in Spain. ${ }^{(7)}$ In addition, more than half of the respondents in our survey had heard about nonnicotinic therapies for smoking cessation, our results being far more significant than those found in the European study. ${ }^{(7)}$

In the present study, the prevalence of cigarette smoking among the respondents was lower when compared with the results of a study carried out in India (5.23\% vs. $13.4 \%)^{(14)}$; in addition, the proportion of our medical students experimenting with tobacco products other than cigarettes was almost half of that reported in the same study ( $21.23 \%$ vs. $40.5 \%)$. However, the frequency of experimenting with waterpipe tobacco smoking was significantly higher among our medical students $(43.82 \%)$ than it was among medical students in Turkey and in Lebanon $(28.6 \%$ and $29.5 \%$, respectively). ${ }^{(18)}$

Although the vast majority of our medical students recognized the importance of smoking cessation counseling (regarding all forms of tobacco products), more than $40 \%$ had already tried water-pipe tobacco smoking. Among young people, there is a common belief that water-pipe tobacco smoking is less harmful to health than are traditional cigarettes. Educational and warning campaigns about the harms caused by the use of and experimentation with these types of products are urgent.

In 2009, the state of São Paulo, Brazil, enacted the Antismoking Law, creating smoke-free environments and banning the use of any smoking product, derived or not from tobacco, in all public and private enclosed places. Our study was conducted between 2008 and 2012, i.e., most of the study was carried out after that law came into force in the state, where our school of medicine is located. During that period, several educational campaigns were conducted to warn the population about the harms of secondhand tobacco smoke. This could have had a positive effect on the results in the present study. ${ }^{(9,19)}$

The main limitation of the present study was that it involved third-year medical students, who might not have received all the information and training regarding tobacco cessation programs. It is expected that such topics should be covered by the end of medical undergraduate courses. Studies comparing the medical curriculum in the third year with that in the last year have yet to be conducted.

Public tobacco control polices require that future physicians be prepared to take their key role in preventing smoking initiation and promoting smoking cessation. The results of the present study are encouraging; however, we need to emphasize to our students the importance of raising the prices of and taxes on tobacco products. We also need to make students aware of the dangers of experimenting with tobacco products other than cigarettes, particularly water-pipe tobacco smoking. Another point that deserves more attention and should be addressed even in the third-year medical curriculum involves the reasons why people smoke and the importance of providing educational materials to the population. Finally, it is strongly recommended that medical schools implement training in nicotine dependence treatment and reinforce the importance of a continuous, during medical visits, to motivate smokers to quit smoking.

\section{REFERENCES}

1. Eriksen M, Mackay J, Schluger N, Gomeshtapeh FI, Drope J. The Tobacco Atlas, 5th edition [monograph on the Internet]. Atlanta: American Cancer Society; 2015 [cited 2017 Jan 11]. [Adobe Acrobat document, 46p.]. Available from: http://3pk43×313ggr4cy0lh3tctjh wpengine.netdna-cdn.com/wp-content/uploads/2015/03/TA5_2015_ WEB.pdf

2. Fiore MC, Bailey WC, Cohen SJ, Dorfman SF, Goldstein MG, Gritz ER, et al. Clinical Practice Guideline. Treating Tobacco Use and Dependence. [monograph on the Internet]. Rockville, MD: U.S Department of Health and Human Services. Public Health Service 2000 [cited 2017 Jan 11]. [Adobe Acrobat document, 196p.] Available from: http://www.treatobacco.net/en/uploads/documents/ Treatment $\% 20$ Guidelines/USA\%20treatment $\% 20$ guidelines $\% 20$ in\%20English\%202000.pdf

3. World Health Organization; Framework Convention on Tobacco Control. Tobacco Free Initiative (TFI) MPOWER. Geneva: World

Health Organization; 2013.

4. Framework Convention on Tobacco Control; World Health Organization. Adopted guidelines. Geneva: World Health Organization; 2013

5. Global Tobacco Surveillance System Collaborating Group. Globa Tobacco Surveillance System (GTSS): purpose, production, and potential. J Sch Health. 2005;75(1):15-24. https://doi. org/10.1111/j.1746-1561.2005.tb00004.x

6. Cauchi D, Mamo J. Smoking health professional student: an attitudinal challenge for health promotion? Int J Environ Res Public Health. 2012;9(7):2550-61. https://doi.org/10.3390/ijerph9072550

7. La Torre G, Saulle R, Unim B, Angelillo IF, Baldo V, Bergomi M, et al. Knowledge, attitudes, and smoking behaviours among physicians specializing in public health: a multicentre study. Biomed Res Int 2014;2014:516734. https://doi.org/10.1155/2014/516734 
8. International Tobacco Control Policy Evaluation Project [homepage on Internet]. Waterloo, Canada: University of Waterloo [updated 2015 Mar 1; cited 2017 Jan 11]. Brazil Timeline of Tobacco Control Policies and ITC Surveys [Adobe Acrobat document, 1p.]. Available from: $\quad$ http://www.itcproject.org/sites/default/files/files/BR\%20 \%28MB-March11,2015\%29.pdf

9. Campaign for Tobacco-Free Kids [homepage on the Internet]. Washington, DC: the Campaign [cited 2017 Jan 11]. Tobacco Control Success Story: Brazil [Adobe Acrobat document, 2p.]. Available from: http://global.tobaccofreekids.org/files/pdfs/en/Brazil_Success_Story_ TC_en.pdf

10. Levy D, de Almeida LM, Szklo A. The Brazil SimSmoke policy simulation model: the effect of strong tobacco control policies on smoking prevalence and smoking-attributable deaths in a middle income nation. PLoS Med. 2012;9(11):e1001336. https://doi. org/10.1371/journal.pmed.1001336

11. Saulle R, Bontempi C, Baldo V, Boccia G, Bonaccorsi G, Brusaferro $S$, et al. GHPSS multicenter Italian survey: smoking prevalence, knowledge and attitudes, and tobacco cessation training among third-year medical students. Tumori. 2013;99(1):17-22.

12. Ministério da Saúde; Secretaria de Vigilância em Saúde; Núcleo de Pesquisas Epidemiológicas em Nutrição e Saúde; Universidade São Paulo [homepage on the Internet]. São Paulo: o Ministério [cited 2017 Jan 11]. Vigitel Vigilância de fatores de risco e proteção para doenças crônicas por inquérito telefônico; 2014. [Adobe Acrobat document, 41p.]. Available from: http://portalsaude.saude.gov.br/
images/pdf/2014/abril/30/Lancamento-Vigitel-28-04-ok.pdf

13. Bader $P$, Boisclair D, Ferrence R. Effects of tobacco taxation and pricing on smoking behavior in high risk populations: a knowledge synthesis. Int J Environ Res Public Health. 2011;8(11):4118-39. https://doi.org/10.3390/ijerph8114118

14. Surani NS, Pednekar MS, Sinha DN, Singh G, Warren CW, Asma S, et al. Tobacco use and cessation counseling in India-data from the Global Health Professions Students Survey, 2005-09. Indian J Cancer. 2012:49(4):425-30. https://doi.org/10.4103/0019-509X.107751

15. Szklo AS, Sampaio MM, Martins LF, Fernandes EM, Almeida LM. O tabagismo no contexto dos futuros profissionais de saúde do Rio de Janeiro. Rev Bras Cancerol. 2011;57(3):321-7.

16. Reichert J, Araújo AJ, Gonçalves CM, Godoy I, Chatkin JM, Sales MP, et al. Smoking cessation guidelines-2008. J Bras Pneumol. 2008;34(10):845-80. https://doi.org/10.1590/S180637132008001000014

17. Warren CW, Lee J, Lea V, Goding A, O'Hara B, Carlberg M, et al. Evolution of the Global Tobacco Surveillance System (GTSS) 19982008. Glob Health Promot. 2009;16(2 Suppl):4-37. https://doi. org/10.1177/1757975909342181

18. Poyrazoğlu S, Sarli S, Gencer Z, Günay O. Waterpipe (narghile) smoking among medical and non-medical university students in Turkey. Ups J Med Sci. 2010;115(3):210-6. https://doi.org/10.3109/ 03009734.2010 .487164

19. Governo do Estado de São Paulo, Lei 13541/09. Lei Antifumo do Estado de São Paulo. (7 May, 2009). 